\title{
Editorial
}

\section{The conceptual framework of the Intergovernmental Platform on Biodiversity and Ecosystem Services/IPBES}

Carlos Alfredo Joly

Biology Institute/UNICAMP-State University of Campinas - Chairman of BIOTA/FAPESP Program

1. Human life would not be possible without biodiversity and ecosystems. The intervention in nature by human societies to meet their needs, however, has modified the composition, structure and functions of ecosystems and has caused detrimental changes that seriously threaten the long term sustainability of societies around the world. In many cases, biodiversity loss and poverty are trapped in a mutually reinforcing vicious circle. Overall, the efforts made on conservation and on the sustainable use of biodiversity and ecosystems have not kept pace with increasing human pressures. A stronger response by Governments, public organizations, communities, the private sector, households and individuals thus requires an improved understanding of such pressures and concerted action to change them.

2. The goal of the Intergovernmental Platform on Biodiversity and Ecosystem Services is to "strengthen the sciencepolicy interface for biodiversity and ecosystem services for the conservation and sustainable use of biodiversity, long-term human well-being and sustainable development". To achieve this goal, the Platform has four functions: to catalyse the generation of new knowledge; to produce assessments of existing knowledge; to support policy formulation and implementation; and to build capacities relevant to achieving its goal. These interconnected functions are realized in the Platform work programme. A conceptual framework for biodiversity and ecosystems services is required to support the analytical work of the Platform, to guide the development, implementation and evolution of its work programme, and to catalyse a positive transformation in the elements and interlinkages that are the causes of detrimental changes in biodiversity and ecosystems and subsequent loss of their benefits to present and future generations.

3. The conceptual framework (diagram presented in the cover of this issue) is a highly simplified model of the complex interactions between the natural world and human societies. The model identifies the main elements, together with their interactions, that are most relevant to the Platform's goal and should therefore be the focus for assessments and knowledge generation to inform policy and the required capacity building. The Platform recognizes and considers different knowledge systems, including indigenous and local knowledge systems, which can be complementary to science-based models and can reinforce the delivery of the functions of the Platform. In this sense, the conceptual framework is a tool for the achievement of a shared working understanding across different disciplines, knowledge systems and stakeholders that are expected to be active participants in the Platform. A full alignment between the categories of different knowledge systems or even disciplines is probably unattainable. The Platform's conceptual framework is intended, however, to be a basic common ground, general and inclusive, for coordinated action towards the achievement of the ultimate goal of the Platform. Within these broad and transcultural categories, different Platform activities may identify more specific subcategories associated with knowledge systems and disciplines relevant to the task at hand, without losing view of their placement within the general conceptual framework.

4. The Platform's conceptual framework includes six interlinked elements constituting a social ecological system that operates at various scales in time and space: nature; nature's benefits to people; anthropogenic assets; institutions and governance systems and other indirect drivers of change; direct drivers of change; and good quality of life.

5. "Nature" in the context of the Platform refers to the natural world with an emphasis on biodiversity. Within the context of science, it includes categories such as biodiversity, ecosystems, ecosystem functioning, evolution, the biosphere, humankind's shared evolutionary heritage, and biocultural diversity. Within the context of other knowledge systems, it includes categories such as Mother Earth and systems of life. Other components of nature, such as deep aquifers, mineral and fossil reserves, wind, solar, geothermal and wave power, are not the focus of the Platform. Nature contributes to societies through the provision of benefits to people (instrumental and relational values, see below) and has its own intrinsic values, that is, the value inherent to nature, independent of human experience and evaluation and thus beyond the scope of anthropocentric valuation approaches.

6. "Anthropogenic assets" refers to built-up infrastructure, health facilities, knowledge (including indigenous and local knowledge systems and technical or scientific knowledge, as well as formal and non formal education), technology (both physical objects and procedures), and financial assets, among others. Anthropogenic assets have been highlighted to emphasize that a good life is achieved by a co production of benefits between nature and societies. 
7. "Nature's benefits to people" refers to all the benefits that humanity obtains from nature. Ecosystem goods and services, considered separately or in bundles, are included in this category. Within other knowledge systems, nature's gifts and similar concepts refer to the benefits of nature from which people derive a good quality of life. Aspects of nature that can be negative to people, such as pests, pathogens or predators, are also included in this broad category. All nature's benefits have anthropocentric value, including instrumental values - the direct and indirect contributions of ecosystem services to a good quality of life, which can be conceived in terms of preference satisfaction, and relational values, which contribute to desirable relationships, such as those among people and between people and nature, as in the notion of "living in harmony with nature".

8. Anthropocentric values can be expressed in diverse ways. They can be material or non-material, can be experienced in a non-consumptive way, or consumed; and they can be expressed from spiritual inspiration to market value. They also include existential value (the satisfaction obtained from knowing that nature continues to be there) and future-oriented values. The latter include bequest value - in other words, the preservation of nature for future generations - or the option values of biodiversity as a reservoir of yet-to-be discovered uses from known and still unknown species and biological processes, or as a constant source, through evolutionary processes, of novel biological solutions to the challenges of a changing environment. Nature provides a number of benefits to people directly without the intervention of society, for example the production of oxygen and the regulation of the Earth's temperature by photosynthetic organisms; the regulation of the quantity and quality of water resources by vegetation; coastal protection by coral reefs and mangroves; and the direct provision of food or medicines by wild animals, plants and microorganisms.

9. Many benefits, however, depend on or can be enhanced by the joint contribution of nature and anthropogenic assets. For example, some agricultural goods such as food or fibre crops depend on ecosystem processes such as soil formation, nutrient cycling, or primary production as well as on social intervention such as farm labour, knowledge of genetic variety selection and farming techniques, machinery, storage facilities and transportation.

10. Trade-offs between the beneficial and detrimental effects of organisms and ecosystems are not unusual and they need to be understood within the context of the bundles of multiple effects provided by them within specific contexts. For example, wetland ecosystems provide water purification and flood regulation but they can also be a source of vector-borne disease. In addition, the relative contribution of nature and anthropogenic assets to a good quality of life varies according to the context. For example, the level at which water filtration by the vegetation and soils of watersheds contributes to quality of life in the form of improved health or reduced treatment costs is based in part on the availability of water filtration by other means, for example treating water in a built facility. If there are no alternatives to watershed filtration by vegetation, then it will contribute strongly to good lives. If there are cost-effective and affordable alternatives, water filtration by vegetation may contribute less.

11. "Drivers of change" refers to all those external factors that affect nature, anthropogenic assets, nature's benefits to people and a good quality of life. They include institutions and governance systems and other indirect drivers and direct drivers (both natural and anthropogenic).

12. "Institutions and governance systems and other indirect drivers" are the ways in which societies organize themselves, and the resulting influences on other components. They are the underlying causes of environmental change that are exogenous to the ecosystem in question. Because of their central role, influencing all aspects of human relationships with nature, these are key levers for decision-making. Institutions encompass all formal and informal interactions among stakeholders and social structures that determine how decisions are taken and implemented, how power is exercised, and how responsibilities are distributed. Institutions determine, to various degrees, the access to, and the control, allocation and distribution of components of nature and anthropogenic assets and their benefits to people. Examples of institutions are systems of property and access rights to land (e.g., public, common-pool, private), legislative arrangements, treaties, informal social norms and rules, including those emerging from indigenous and local knowledge systems, and international regimes such as agreements against stratospheric ozone depletion or the protection of endangered species of wild fauna and flora. Economic policies, including macroeconomic, fiscal, monetary or agricultural policies, play a significant role in influencing people's decisions and behaviour and the way in which they relate to nature in the pursuit of benefits. Many drivers of human behaviour and preferences, however, which reflect different perspectives on a good quality of life, work largely outside the market system.

13. "Direct drivers", both natural and anthropogenic, affect nature directly. "Natural drivers" are those that are not the result of human activities and are beyond human control. These include earthquakes, volcanic eruptions and tsunamis, extreme weather or ocean-related events such as prolonged drought or cold periods, tropical cyclones and floods, the El Niño/La Niña Southern Oscillation and extreme tidal events. The direct anthropogenic drivers are those that are the result of human decisions, namely, of institutions and governance systems and other indirect drivers. Anthropogenic drivers include habitat conversion, e.g., degradation of land and aquatic habitats, deforestation and afforestation, exploitation of wild populations, climate change, pollution of soil, water and air and species introductions. Some of these drivers, such as pollution, can have negative impacts on nature; others, as in the case of habitat restoration, or the introduction of a natural enemy to combat invasive species, can have positive effects. 
14. "Good quality of life" is the achievement of a fulfilled human life, a notion which varies strongly across different societies and groups within societies. It is a context-dependent state of individuals and human groups, comprising access to food, water, energy and livelihood security, and also health, good social relationships and equity, security, cultural identity, and freedom of choice and action. From virtually all standpoints, a good quality of life is multidimensional, having material as well as immaterial and spiritual components. What a good quality of life entails, however, is highly dependent on place, time and culture, with different societies espousing different views of their relationships with nature and placing different levels of importance on collective versus individual rights, the material versus the spiritual domain, intrinsic versus instrumental values, and the present time versus the past or the future. The concept of human well-being used in many western societies and its variants, together with those of living in harmony with nature and living well in balance and harmony with Mother Earth, are examples of different perspectives on a good quality of life.

As approved at the 2nd Plenary of IPBES, Antalya, Turkey 9 to 14 December 2013 